\title{
EL NIÑO JESÚS DEL RETABLO DE LA VIRGEN DE BELÉN DE LA IGLESIA DE LA ANUNCIACIÓN DE SEVILLA
}

\section{THE CHILD JESUS FROM THE VIRGIN OF BETHLEHEM'S ALTARPIECE AT THE ANNUNCIATION'S CHURCH IN SEVILLE}

\author{
Rosario Marchena Hidalgo \\ Universidad de Sevilla. España \\ romahi@us.es
}

\begin{abstract}
En la iglesia de la Anunciación de Sevilla, actualmente patrimonio de la Universidad, el retablo más antiguo que se conserva es el de la Virgen de Belén, compuesto por veinte tablas de distinto tamaño, cronología, autor y procedencia. De entre ellas sobresale la Virgen de la Leche y un pequeño Niño Jesús que estuvo pintado en momentos anteriores a 1838 en la puerta de un sagrario.

Palabras clave: iglesia de la Anunciación de Sevilla; retablo de la Virgen de Belén; sagrario; Niño Jesús; Andrés Ramírez.
\end{abstract}

The oldest preserved altarpiece at the Annunciation's Church in Seville, now heritage of the University, is that of the Virgin of Bethlehem, composed of twenty boards of different sizes, chronology, author and origin. The Virgin of the Milk and a small Child Jesus who was painted before 1838 at the door of a tabernacle stands among them.

Keywords: Annunciation's Church in Seville; Virgin of Bethlehem altarpiece; tabernacle; Child Jesus; Andrés Ramírez.

En la iglesia de la Anunciación de Sevilla, patrimonio jesuítico hasta la promulgación de la Pragmática Sanción de Carlos III en 1767 y desde entonces, por concesión real, de la Universidad, que tomó posesión de él el 31 de diciembre de 1771, se encuentra el retablo de la Virgen de Belén, situado actualmente en el muro del evangelio en un nicho un poco holgado para su tamaño ${ }^{1}$. Es un retablo

\footnotetext{
${ }^{1} 5,57 \times 2,58 \mathrm{~m}$.
} 
clasicista y lineal que se compone de un pequeño banco, de menos de 30 centímetros de altura, dos cuerpos de tres calles y ático. Una serie de elementos arquitectónicos enmarcan los distintos espacios: dobles columnas corintias flanquean los dos cuerpos, pilastras del mismo orden delimitan la calle central y el ático y un frontón roto corona este último (Figura 1).

El retablo se encuentra en bastante mal estado de conservación como consecuencia del tiempo, pues es la pieza más antigua existente en la iglesia de la Anunciación. También han debido de contribuir las varias recomposiciones y traslados que ha sufrido dentro del mismo templo. Todo ello se ha traducido en que el retablo tiene un aspecto degradado, sucio y sus dorados muestran distintas intensidades denotando las diferentes épocas y calidades. Solo la tabla central, la Virgen de Belén, que le da el nombre actual al retablo, se ve resplandeciente, pues en la última década del pasado siglo fue rescatada del depósito del Museo de Bellas Artes, donde se encontraba desde hacía más de veinte años, y restaurada ${ }^{2}$. La peor parte, sin duda, se la ha llevado el banco, que muestra un aspecto desvencijado pues sus tablitas parecen prontas a desarmarse, estando algunas abiertas por separación de las piezas que las componen, como la de la Adoración de los Magos, o apolilladas, como la de los Desposorios de la Virgen. Pese a todo ello, como decía Amador de los Ríos, "el retablo es digno de llamar detenidamente la atención de los hombres instruidos en arte" 3 .

Este magnífico ejemplar acoge veinte tablas pintadas, once en el banco y nueve en el resto del retablo, de distinto tamaño, cronología, autor y procedencia, que tienen como tema la vida de la Virgen. Se inicia el relato en el banco con el Nacimiento de María, la Presentación en el templo, los Desposorios, la Anunciación, la Natividad y la Adoración de los Magos. En el frente de los pedestales de las columnas y las pilastras hay cuatro santos, cada uno de ellos con su correspondiente nombre: San Bernardo, San Ignacio Mártir o de Antioquía entre dos leones, San Buenaventura y San Dionisio Areopagita. La tabla central del banco muestra un precioso Niño Jesús. En la calle central del primer cuerpo está la Virgen de la Leche o Virgen de Belén, atribuida a Marcelo Coffermans ${ }^{4}$. A los lados, tablas de menor altura, superpuestas, San Juan Evangelista y San Joaquín a su derecha y San Juan Bautista y Santa Ana a su izquierda. El segundo cuerpo tiene en su calle central la Asunción flanqueada por San Agustín y San Francisco. El ático está ocupado por una sola tabla que representa a la Trinidad disponiéndose a coronar a la Virgen. Si a lo largo del banco se relatan de izquierda a derecha

2 AA.VV.: Exposición Universitas Hispalensis. Patrimonio de la Universidad de Sevilla. Sevilla, 1995, p. 27.

3 AMADOR DE LOS RÍOS, José: Sevilla pintoresca o Descripción de sus más célebres monumentos artísticos. Sevilla, 1844, p. 236.

${ }^{4}$ BERMEJO, Elisa: "Influencia de una obra de Francisco Pacheco", Archivo Español de Arte, 217, 1982, p. 3. 
escenas de la vida de María, las tres tablas de la calle central continúan el relato de abajo arriba con la Virgen y el Niño, la Asunción y la Coronación. Todos los personajes que aparecen en este retablo tienen ganado su lugar en él por la relación existente con María: San Bernardo, porque Ella le dio leche de su pecho; San Ignacio de Antioquía, porque en sus escritos defiende la virginidad de María; San Buenaventura, por el amor que le profesó siempre; San Dionisio Areopagita, porque asistió a la dormición de la Virgen; San Agustín, por su sermón $215^{5}$ en el que analiza la encarnación del Hijo de Dios en madre humana; y San Francisco, por mostrar una intensa devoción a la mujer que nos trajo a Dios como hombre. Es evidente que el que compuso este retablo con piezas de distinta cronología y autor, creando un conjunto de gran coherencia temática, era un experto en temas eclesiásticos y esa persona fue, con toda probabilidad, el deán López Cepero que, en palabras de Cisneros Lanuza, lo amplió y restauró.

Las noticias más antiguas referidas a este retablo aparecen tras la transformación del interior de la iglesia que consistió básicamente en la eliminación de pinturas y altares barrocos emprendida por don Manuel López Cepero entre 1836 y $1842^{7}$. De 1844 son las de Amador de los Ríos y González de León, cuando acababa de terminarse la "limpieza". Nueve años después, De Cisneros Lanuza repite, punto por punto, partes enteras de las obras de los anteriormente citados escritores. Todos coinciden en que "perteneció este retablo a una de las antiguas capillas, titulada de las reliquias" " "formada debajo de la torre", de donde en 1838, después de eliminado el altar de San Ignacio, pasó al brazo del evangelio del transepto tras haber sido compuesto con tablas de distinta procedencia ${ }^{10}$. En los años 70 del pasado siglo, despojado de todo el aparato con que se le había ampliado para que se asemejara al frontero altar de la Concepción, se trasladó al lado del evangelio de la nave.

Martín Villa, en 1886, amplía las referencias que de este altar tenemos describiendo su estructura, la temática de sus pinturas e incluso dando algunas medidas ${ }^{11}$. El conocimiento del aspecto que tuvo desde 1838 lo completa una fo-

${ }^{5}$ SAN AGUSTÍN: Obras completas de San Agustín. 24, Sermones 4, 184-272 B. Sermones de los tiempos litúrgicos. Madrid, 1983, pp. 177-186.

${ }^{6}$ DE CISNEROS LANUZA, Antonio María: Una visita a la iglesia de la Universidad Literaria de Sevilla en 1853. Sevilla, 1853, p. 35.

${ }^{7}$ ROS GONZÁLEZ, Francisco S.: "Manuel López Cepero y la reforma de la iglesia de la Universidad de Sevilla", Laboratorio de Arte, 19, 2006, pp. 421-452.

${ }^{8}$ AMADOR DE LOS RÍOS, José: Sevilla pintoresca..., op. cit., p. 235.

${ }^{9}$ GONZÁLEZ DE LEÓN, Félix: Noticia artística, histórica y curiosa de todos los edificios públicos sagrados y profanos de este muy noble, muy leal, muy heroica e invicta Ciudad de Sevilla. T. I. Sevilla, 1844, p. 214.

10 AMADOR DE LOS RIOS, José: Sevilla pintoresca..., op. cit., pp. 232-233.

${ }^{11}$ MARTÍN VILLA, Antonio: Reseña histórica de la Universidad de Sevilla y descripción de su iglesia. Sevilla, 1886, pp. 106-108. 
tografía de la fototeca del Laboratorio de Arte de la Universidad de Sevilla hecha por Francisco Murillo Herrera en $1910^{12}$ en la que se aprecia el ancho zócalo ${ }^{13}$ del que todos los escritores que se ocupan de este tema hablan pero al que Martín Villa dedica algo más de atención: "El indicado zócalo consta de cinco lienzos del tamaño de tres cuartas de largo. El de enmedio representa al Salvador y los otros cuatro contienen la historia del martirio de San Cosme y San Damián, a saber: la cura hecha en un hospital, la prisión donde reciben los consejos de un ángel, los azotes y, por último, la hoguera; todos, según parece son de Alonso Cano, aunque no de su mejor tiempo"14. Cuatro de las cinco pinturas del ancho zócalo procedían de un retablo, desmontado en las actuaciones del deán López Cepero, que se colocó en la iglesia de la Anunciación en 1657 según recoge el jesuita Antonio de Solís: "Logramos este año el beneficio de tener en nuestra iglesia altar consagrado a los Santos Mártires Cosme y Damián a quien debe nuestra religión mil favores" $" 15$.

No hay ninguna noticia anterior a esta sobre el retablo. En la obra de Antonio de Solís, que tanta información fundamental aporta sobre muchos aspectos de la casa jesuítica en Sevilla, poniendo "a la vista como fijos los sucesos, las alhajas o prendas de que se ha ido adornando nuestra casa y cómo y cuándo se colocaron" $"$, no se hace mención alguna de este retablo pese a que el autor dice haber recurrido a antiguos papeles para recuperar la historia de la casa profesa. Es cierto que en la obra se va hablando de qué, cuándo y por iniciativa de quién se van levantando los altares, pero el primero que aparece es el mayor en $1606^{17} \mathrm{y}$ el que nos ocupa es anterior.

De la destrucción de los antiguos altares se salvaron el mayor y el de la Concepción, situado en el lado de la epístola del crucero, porque encajaban en el esquema clasicista del momento de la actuación sobre el templo. En el lado del evangelio, enfrentado a este último, se instaló de nuevo el procedente de la capilla de las reliquias que fue ampliado y restaurado por don Manuel López Cepero

${ }_{12}$ Fototeca de la Universidad de Sevilla, $\mathrm{n}^{\circ}$ de registro 4-50.

$1387 \mathrm{~cm}$ de altura mínima.

${ }^{14}$ MARTÍN VILLA, Antonio: Reseña histórica..., op. cit., pp. 106-107.

${ }_{15}$ BUS (Biblioteca de la Universidad de Sevilla), A331/219, DE SOLÍS Y FEDERIGUI, Antonio: Los dos espejos que representan los dos siglos que han pasado de la fundación de la Casa Profesa de la Compañia de Jesús en Sevilla. Y sujetos que han florecido y muerto en ella con las noticias historiales de cada año que a ella pertenecen y que expone a la vista de todos. Manuscrito, 1755, p. 38. Es copia del año 1907 de la del colegio de los jesuitas del Palo (Málaga). Esta obra ha sido publicada en MOLINA GARCÍA, Leonardo (ed.): Los Dos Espejos. Historia de la Casa Profesa de la Compañia de Jesús de Sevilla durante los dos primeros siglos, 1550-1767. Sevilla, 2010.

${ }^{16}$ Ibidem, op. cit., p. 7.

${ }^{17}$ Ibid, p. 227. 
"guardando uniformidad en cuanto era posible con el de la Concepción"18 para conseguir lo cual se le había agregado unos adornos exteriores análogos y el ancho zócalo que describe Martín Villa. En el traslado último se eliminó este zócalo, pese a la valoración positiva que todos los estudiosos habían hecho del Salvador, llegando incluso a atribuírsela a Alonso $\mathrm{Cano}^{19}$, y esta tabla fue a parar al Rectorado de la antigua Fábrica de Tabacos mientras que las otras cuatro, las de San Cosme y San Damián, terminaron en la capilla universitaria.

Sin embargo, en el actual retablo de la Virgen de Belén, hay otras pinturas más que no debieron pertenecer al conjunto original. Aunque Amador de los Ríos dice que está formado por tablas de diferentes épocas ${ }^{20}$, Martín Villa mantiene que el centro del retablo contiene íntegro el antiguo altar ${ }^{21}$, es decir, que tenía esa misma estructura en su lugar de origen, la capilla de las reliquias, pero no debe ser así pues actualmente hay dos tablas ${ }^{22}$ en el banco del retablo de la Concepción, la Circuncisión, que reproduce punto por punto un grabado de Cornelis Cort, fuente de inspiración para buena parte de las pinturas del retablo de la Virgen de Belén ${ }^{23}$, y la Visitación, que son de la misma mano que algunas de las pinturas del altar que nos ocupa, por lo que debieron pertenecer al mismo conjunto original. Además, estas dos tablas presentan el mismo grado de deterioro, apolilladas, rajadas por separación de las piezas que la componen, que las del banco del retablo que estamos estudiando.

El altar de la Virgen de Belén es del siglo XVI pero no de un solo momento. La obra en sí misma aporta una fecha recogida en una de las tablitas del banco, la Anunciación, que reproduce un grabado de Cornelis Cort. Sobre el atril en el que se arrodilla la Virgen aparece la inscripción "mense junii 1588" (Figura 2), fecha que se ha atribuido al retablo completo, pero existen otras diferentes. El cuadro central, de una vara de longitud ${ }^{24}$, que muestra a la Virgen dando de mamar al Niño, atribuido a Marcelo Coffermans, es de alrededor de 1560. Esa misma fecha debe corresponder a la tablita del Niño Jesús que se encuentra en el centro del banco y que, por sus dimensiones, su estilo, sus oros bruñidos y el distinto tamaño que muestra la figura respecto a las otras del resto de las pinturas, se aprecia que no pertenece al conjunto. Por último, la tabla de la Santa Trinidad, pese

${ }^{18}$ DE CISNEROS LANUZA, Antonio María: Una visita..., op. cit., p. 35.

19 AMADOR DE LOS RÍOS, José: Sevilla pintoresca..., op. cit., p. 235.

${ }^{20}$ Ibidem.

${ }^{21}$ MARTÍN VILLA, Antonio: Reseña histórica..., op. cit., p. 107.

$2242,5 \mathrm{x} 47 \mathrm{~cm}$.

${ }^{23}$ El empleo de los grabados de Cort se aprecia principalmente en las tablas de la Trinidad, la Asunción, la Estigmatización de San Francisco, el Nacimiento de la Virgen, los Desposorios y la Anunciación. NAVARRETE PRIETO, Benito: La pintura andaluza del siglo XVII y sus fuentes grabadas. Madrid, 1998, p. 114.

${ }^{24}$ MARTÍN VILLA, Antonio: Reseña histórica..., op. cit., p. 107. 
a que encaja perfectamente en la línea argumental del retablo, quizás sea la de la Congregación de los Caballeros del Espíritu Santo, instituida en 1578 por Enrique III de Francia, que se dedicó y colocó el 1 de noviembre de 1606 en la sacristía, que "hoy es la que llamamos de las reliquias" 25 , donde hacían sus devociones. El retablo ha sido atribuido por González de León ${ }^{26}$ y Martín Villa ${ }^{27}$ a Pacheco, pero Amador de los Ríos, que recoge en su obra esta autoría, no le da demasiada credibilidad: "El pertenecer a una época en que florecía Francisco Pacheco y gozar este sabio profesor de grande autoridad entre sus compatriotas, así como la semejanza que se advierte entre su estilo y la manera de la mayor parte de las tablas, de que nos ocupamos, han dado motivo alguno para sospechar que sean obras de aquel artista. Más nosotros carecemos de dato alguno y en obsequio de la brevedad, no queremos detenernos en hacer conjeturas más o menos probables sobre este asunto" 28 . En el retablo, aparte de la de la Virgen de Belén, se han querido ver dos manos, una es la de las pinturas del banco y otra, la del resto $^{29}$. Sin embargo, algunas tablas del cuerpo del retablo muestran su identidad con otras del banco, como se ve especialmente en las tocas de Santa Ana y las de la Virgen de la Presentación en el templo.

En la actualidad la autoría de Pacheco la defiende Navarrete Prieto basándose en los parecidos formales existentes entre las tablas sevillanas y la primera obra conservada de este pintor, Cristo camino del Calvario, de 1589, siendo el más llamativo la semejanza existente entre el Dios Padre de este cuadro y el de la Trinidad del ático del retablo. Otro argumento empleado por este autor para reforzar su teoría es que la firma del cuadro de Cristo camino del Calvario presenta la misma grafía que la inscripción del atril sobre el que se arrodilla la Virgen de la Anunciación ${ }^{30}$. Valdivieso, aunque reconoce que induce a pensar en la autoría de Pacheco el que en 1590 pintase, fechase y firmase una copia de la Virgen de Belén para la catedral de Granada, piensa que el estilo del retablo es diferente y superior al que el artista tenía por esos años, que se ignora el autor, que no puede ponerse en relación y que puede ser obra del círculo de Vasco Pereira ${ }^{31}$.

El altar responde con claridad a un mismo programa iconográfico pero para completarlo se ha recurrido a pinturas de momentos diferentes a los de 1588. El

${ }^{25}$ DE SOLÍS Y FEDERIGUI, Antonio: Los dos espejos..., op. cit., pp. 263 y 317.

${ }^{26}$ GONZÁLEZ DE LEÓN, Félix: Noticia histórica..., op. cit., p. 220.

7 MARTÍN VILLA, Antonio: Reseña histórica..., op. cit., p. 107.

${ }_{28}$ AMADOR DE LOS RÍOS, José: Sevilla pintoresca..., op. cit., p. 236.

${ }^{29}$ MORALES, Alfredo; SANZ, María Jesús; y VALDIVIESO, Enrique: Guía artística de Sevilla y su provincia. Sevilla, 1989, p. 150.

${ }^{30}$ NAVARRETE PRIETO, Benito: La pintura andaluza..., op. cit., pp. 114-115.

${ }^{31}$ FALCÓN, Teodoro; BERNALES, Jorge; VALDIVIESO, Enrique; y SANZ, María Jesús: Universidad de Sevilla: patrimonio monumental y artístico: arquitectura, escultura, pintura y artes ornamentales. Sevilla, 2001, p. 141, nota 2 y p. 105. 
caso más notorio es el de la Virgen de Belén, a la que, para que encajara en el hueco destinado a ella que era más grande, se le amplió el marco dorado. Pero existe otro caso que es el del Niño Jesús que centra el banco (Figura 3). Esta tabla era la puerta de un sagrario a la que se ha cegado la bocallave y la huella de las bisagras para adaptarla a su nueva función. En una fotografía realizada con rayos ultravioletas se aprecia muy bien la actuación sobre la pintura, en la que destaca el desgaste del oro en la bocallave y en las bisagras (Figura 4). La tablita del Niño Jesús que se encuentra en el centro del banco del retablo no pertenece a la misma época en la que encajan la mayoría de las diecinueve tablas restantes y presenta discordancias con las otras pinturas. La primera de ellas es el tamaño, pues la del Niño Jesús mide $28 \mathrm{~cm}$ de alto frente a los 24,5 del resto de las tablas del banco. Tampoco la anchura es semejante a ninguna otra pues, aunque predominan los 26 o $26,5 \mathrm{~cm}^{32}$, las hay de mayor tamaño, 35 o $35,5^{33}$, y de mucho menor, $10 \mathrm{u} 11^{34}$. Todo el retablo está compuesto a base de encajar en el espacio disponible pinturas de diferentes medidas, pero eso es mucho más evidente en el banco. Otro aspecto que diferencia la tabla que estamos estudiando es que, mientras el resto de las pinturas van sobre un fondo paisajístico, doméstico o neutro, de encasamientos o de lejos, el Niño Jesús va sobre oro bruñido, desgastado especialmente por los bordes y en el sitio en que, como puerta de sagrario que era, aparecían la bocallave y las bisagras.

El autor de esta obra es el pintor Andrés Ramírez pues los rasgos, la cara mofletuda, el aspecto dulce, el pelo, rubio, con entradas muy acusadas y mechón en el centro de la frente, y la aureola, lo confirman. El parecido que tiene este Niño Jesús con todos los niños representados por él en su obra como iluminador refrendan esta propuesta. Unas veces son Niños Jesús como el de la parte inferior de la orla del libro de coro 41, folio 6 vuelto, de la catedral de Sevilla, otras veces son ángeles tenantes como los del Evangeliario y colectario cartujano, orla inferior del folio 1 vuelto, o músicos como los de la orla exterior del libro de coro 62 de la catedral de Sevilla, folio 2 vuelto (Figura 5), y otras, putti como los de la orla exterior del folio 3 del mismo libro ${ }^{35}$. Especialmente parecido es el Niño Jesús del libro de coro de la catedral de Sevilla 60, folio 7 vuelto (Figura 6) que se muestra desnudo, de frente, sosteniendo con la mano izquierda el globo coronado por la cruz mientras bendice con la derecha. Su rostro es sonriente y sonrosado, su pelo es rubio y lleva unas potencias muy singulares formadas por tres vástagos de los que los exteriores se curvan formando roleos $^{36}$. Este mismo tipo de potencias las

\footnotetext{
${ }^{32}$ Anunciación, Nacimiento, Desposorios y Presentación en el templo.

${ }_{33}$ Nacimiento de la Virgen y Adoración de los Magos.

${ }^{34}$ San Bernardo, San Buenaventura, San Dionisio Areopagita y San Ignacio Mártir.

${ }^{35}$ MARCHENA HIDALGO, Rosario: Las miniaturas de los libros de coro de la catedral de Sevilla: el siglo XVI. Sevilla, 1998, pp. 206, 208 y 188.

${ }^{36}$ Ibidem, pp. 211-212.
} 
usa Andrés Ramírez en una miniatura del libro de coro 40 de la catedral de Sevi1la, folio 1 vuelto, en que San José lleva al Niño de la mano (Figura 7), la primera representación conocida, pues es de 1543, que muestra a ambos en esa actitud ${ }^{37}$.

El modelo de niño desnudo, con nimbo y sosteniendo en su mano el globo terráqueo coronado por la cruz aparece ya en una miniatura del libro de coro 65 de la catedral de Sevilla del iluminador Andrés Gutiérrez de 1529-1531 ${ }^{38}$. Esta, la citada miniatura del libro 60 y el Niño Jesús del banco del retablo de la Virgen de Belén rechazan la propuesta de Réau de que esta representación no se hace clara hasta la Contrarreforma y no se populariza hasta el siglo XVII ${ }^{39}$. La devoción al Niño Jesús, como forma más próxima y asequible de Dios, existió antes de ese momento, aunque fueron los comitentes y los artistas del siglo XVII los que popularizaron el modelo.

Andrés Ramírez es un pintor y miniaturista que, acompañado de su padre, el también pintor Juan Ramírez, aparece en Sevilla en 1532. A partir de ese momento las noticias documentales se suceden tanto de su vida profesional como de su vida privada. El primer aspecto de su vida profesional parece ser el de miniaturista, pues ya en 1532 se concierta con Arnao de Vergara para realizar una tarea de iluminación destinada al monasterio de Santa María de las Cuevas ${ }^{40}$. Cobra de la catedral de Sevilla por la misma función en 1535, 1537, 1543, 1555, 1558, 1559 y $1565^{41}$, aunque los pagos, sumergidos bajo otros conceptos, debieron ser muchos más a juzgar por la gran obra que aún queda de él. La localización de su labor como miniaturista en la catedral de Sevilla permitió establecer unas características y, a través de ellas, reconocer su mano en otros sitios de los que no había constancia documental, como en la catedral de Jaén, la iglesia del Salvador de Sevilla o la Biblioteca Capitular y Colombina ${ }^{42}$.

Pero la miniatura no fue más que una parte de su vida profesional. Él se titula siempre pintor y como tal aparece en los documentos, unas veces concertando trabajos de los que él, junto a otros artistas, sería el autor, otras actuando de fiador de entalladores, pintores, doradores... Es una enorme obra, especialmente abundante en los años 50 y 60 del siglo XVI. Muchos entalladores y pintores aparecen relacionados con Andrés Ramírez, pero entre todos ellos sobresalen, por su

${ }^{37}$ Ibid, pp. 198-199.

${ }^{38} \mathrm{Ibid}$, pp. 140-142. Folio 26 vuelto, parte izquierda de la letra capital $\mathrm{R}$ en la que se encaja la historia de la Resurrección.

39 RÉAU, Louis: Iconographie de l’ Art Chrétien. Part. II, T. II. París, 1955-1957, p. 41.

40 ÁLVAREZ MÁRQUEZ, María del Carmen: El mundo del libro en la iglesia catedral de Sevilla en el siglo XVI. Sevilla, 1992, p. 154.

${ }^{41}$ GESTOSO Y PÉREZ, José: Sevilla monumental y artística. Vol. II. Sevilla, 1890, p. 254; y ÁLVAREZ MÁRQUEZ, María del Carmen: El mundo del libro..., op. cit., pp. 354-355.

${ }^{42}$ MARCHENA HIDALGO, Rosario: Las miniaturas..., op. cit., pp. 217-220. 
intensa y extensa colaboración, cinco artistas que están trabajando en Sevilla en el segundo tercio del siglo XVI: Arnao de Vergara, Hernando de Esturmio, Roque Balduque, Pedro de Villegas Marmolejo y Luis de Vargas ${ }^{43}$.

Desde 1537 los documentos además nos informan con generosidad de su vida privada: bautiza a los hijos de su esclava Catalina y también a su esclavo Hernando, apadrinados por integrantes de un sector acomodado de la sociedad de Sevilla y él mismo apadrina a otros dos niños, uno libre y otro hijo de una esclava, en $1548^{44}$. Las noticias de su vida privada confirman que vivió siempre en la collación de San Miguel, que las relaciones profesionales con otros artistas habían trascendido al plano familiar y que su situación económica era lo suficientemente buena como para tener esclavos. De todos los testimonios referentes a su vida privada, sin duda, el más relevante es su testamento de 19 de septiembre de 1569 en el que dice ser hermano de la cofradía de la Vera Cruz, sita en su capilla del convento de San Francisco, donde ordena ser sepultado. El documento aborda también aspectos de su vida profesional, citando las obras que, ya terminadas, había que cobrar: el retablo de la iglesia de Santa María de Carmona (Sevilla), realizado con Villegas Marmolejo y Antonio Rodríguez; los laterales del retablo de la iglesia de Almonaster la Real (Huelva), realizado con Juan de Zamora; la custodia de la iglesia de la villa de El Pedroso (Sevilla); un retablo; unas andas y un San Juan del monasterio sevillano de San Clemente; y un crucifijo, la Virgen y San Juan de una cofradía de Arcos de la Frontera (Cádiz). Igualmente el testamento recoge la obra en la que está trabajando en ese momento, el aderezo de un retablo de la mujer de Nuño Esquivel para su capilla del monasterio sevillano de Madre de Dios, que terminarían su mujer Catalina Ortiz y sus oficiales ${ }^{45}$.

Todas estas noticias, referidas a un pintor bien considerado a juzgar por la cantidad de obras que contrata y bien relacionado con lo más sobresaliente del mundo artístico sevillano del segundo tercio del siglo XVI, no han servido para localizar su obra pictórica, siendo únicamente un nombre en este campo. Solo se ha hecho una atribución de las pinturas del retablo de Santa Ana de la iglesia de Santa María de la Asunción de Alcalá del Río (Sevilla), basándose en la estrecha relación profesional y personal del entallador Roque Balduque, autor del mismo,

${ }^{43}$ GESTOSO Y PÉREZ, José: Ensayo de un diccionario de los artífices que florecieron en Sevilla desde el siglo XIII al XVIII inclusive. T. III. Sevilla, 1908, pp. 63 y 419; LÓPEZ MARTÍNEZ, Celestino: Desde Jerónimo Hernández hasta Martínez Montañés. Sevilla, 1929, p. 195; HERNÁNDEZ DÍAZ, José: Documentos para la historia del arte en Andalucía. T. VI. Sevilla, 1933, pp. 39-42 y T. IX. Sevilla, 1937, pp. 39-40, 101 y 154; y ÁLVAREZ MÁRQUEZ, María del Carmen: El mundo del libro..., op. cit., p. 154.

${ }^{44}$ APSM (Archivo parroquial de San Miguel), Libro I de Bautismos, 1539-1552, ff. $27 \mathrm{v}, 54 \mathrm{v}, 79 \mathrm{v}, 106 \mathrm{v}, 82 \mathrm{v}$ y $113 \mathrm{r}$.

${ }^{45}$ LÓPEZ MARTÍNEZ, Celestino: Desde Jerónimo Hernández..., op. cit., p. 195. 
con Andrés Ramírez y, principalmente, en los parecidos formales entre las seis tablas y su amplia obra miniaturista ${ }^{46}$.

De todos los documentos exhumados de Andrés Ramírez son especialmente interesantes para el tema que nos ocupa los que se refieren a la construcción de tabernáculos. Unas veces aparece él como fiador del entallador Roque Balduque, que es quien lo concierta: tabernáculos de Omnium Sanctorum, San Lorenzo, San Juan de la Palma, Santa Marina, San Román y San Gi1 ${ }^{47}$. La estrecha colaboración que llevó con Roque Balduque permite suponer que, además de fiador, es también el pintor de toda esta obra. Otras veces él es personalmente el que se obliga a dorar y pintar algunos tabernáculos, como los de las iglesias de San Vicente, Omnium Sanctorum y San Juan de Marchena ${ }^{48}$. Desgraciadamente el fuego consumió las obras a las que se refieren los documentos, en cuyas puertas podía haber pintado un Niño Jesús.

El tabernáculo o sagrario es el lugar donde reside Jesús sacramentado. Suele estar situado en el centro del banco sobre la mesa del altar y, en esencia, es un pequeño recinto cerrado al que se accede por una puerta con llave. A una de esas puertas, a la que se le ha cegado la bocallave, debe corresponder el Niño Jesús que aparece en el retablo de la Virgen de Belén. Los años de ejecución del tabernáculo al que perteneció la tablita deben estar entre los 50 o 60 del siglo XVI, pero eso no es obstáculo para que se encontrara en la sede jesuítica.

La narración del padre Antonio de Solís, que se inicia en 1550, cuenta que, al principio, la comunidad vivió en "posada ajena" durante tres años y medio, en unas casas del conde de Olivares, en Santa María de Gracia, que en 1556 "se compró una casa en el barrio que llamaban de Don Pedro Ponce, collación de San Salvador, antiguo solar de los duques de Medinaceli pero que ahora lo poseía el capitán Hernán Suárez de Alcázar", que durante los dos años siguientes, aunque algunos jesuitas ya habitaban en la nueva, todavía siguieron viviendo en su antigua casa y que, en 1558, se abandonó totalmente y, en la nueva morada, se dispuso iglesia y dos salas para clases ${ }^{49}$. Pese a que algunos datos constatados difieren de los aportados por el cronista, en concreto el de las fechas del establecimiento de la casa de la compañía en Sevilla (1554) y de la compra de la propiedad donde radicaría definitivamente $(1558)^{50}$, el 2 de septiembre de 1565 se puso la primera piedra de la iglesia y en 1579 "estaba en toda perfección acabado nuestro fuerte, espacioso y hermoso templo y solo le faltaba entrarlo a ocupar la

${ }^{46}$ MARCHENA HIDALGO, Rosario: "Andrés Ramírez, pintor del siglo XVI”, Laboratorio de Arte, 21, 2008-2009, pp. 67-88.

${ }^{47}$ HERNÁNDEZ DÍAZ, José: Documentos... T. VI, op. cit., pp. 39-42.

48 Ibidem, T. IX, pp. 39-40.

49 DE SOLÍS Y FEDERIGUI, Antonio: Los dos espejos..., op. cit., pp. 2, 35, 41, 4950 y 54 .

${ }^{50}$ SOLÍS DE LOS SANTOS, José: Expobus. Sala 3. Jesuitas: Casa Profesa, p. 1. 
Majestad de Cristo nuestro bien sacramentado [...] y se determinó se hiciese la dedicación debajo del título de la Encarnación el día de San Juan Evangelista a 27 de diciembre de este año. Debajo de esta disposición, segundo día de Pascua de Navidad por la tarde trasladó el Santísimo Sacramento de la iglesia vieja a la nueva [...] y el día siguiente se dijo la primera misa por el Señor Arzobispo Don Cristóbal de Rojas y Sandoval" ${ }^{51}$. Estas palabras demuestran que existía una iglesia anterior a la actual en la que radicaba el culto, por lo que tenía que tener un tabernáculo al menos desde 1558.

El Niño Jesús del retablo de la Virgen de Belén representa la conjunción perfecta de la gracia infantil y la dignidad divina (Figura 8). No le falta ninguno de los atributos correspondientes a la segunda persona de la Santísima Trinidad. Es el símbolo de la encarnación, paso previo a su muerte en la cruz y posterior resurrección. Está de pie sobre el globo terráqueo, carga el peso de su cuerpo sobre la pierna derecha exonerando la izquierda, bendice a la manera bizantina con la mano derecha mientras que con la izquierda sujeta la cruz. Su cara responde a las de los niños que Andrés Ramírez representa, mofletudos, con las entradas de la frente muy pronunciadas y un mechón de pelo en el centro, si bien aquí la alegre sonrisa y despreocupación de otros se vuelve seriedad reflexiva sobre la misión que ha de desarrollar en su edad adulta. A eso alude también el color de su túnica morada. Rasgo significativo son las potencias de las que destacan los roleos que se enroscan a una y otra parte del vástago central.

Noticias sobre Niños Jesús pintados en las puertas de los sagrarios hay bastantes pertenecientes al siglo XVII. Especialmente parecido al que nos ocupa es el de la puerta del sagrario del retablo del desaparecido colegio de San Basilio, hoy en la iglesia de Santa María de la Oliva de Salteras, que adopta la misma postura, de pie sobre nubes, bendiciendo con la mano derecha mientras sujeta la cruz con la izquierda, y cuya cabeza emite largos rayos. Se diferencia en el color de la túnica, que en este caso es el hábito marrón monacal de los basilios, de mangas anchas y ceñido por una correa, en el tamaño, $44,5 \times 22,5 \mathrm{~cm}$, pues este casi duplica la altura del de la Virgen de Belén, y en que es más aniñado y tierno, resaltando ese momento fugaz que fue la infancia de la vida terrena de Cristo. Esta pintura, de gran belleza y elegancia compositiva, es la única de este tema que se conoce de Francisco de Herrera el Viejo ${ }^{52}$, que responde así a esa corriente que instala al Niño Jesús en las puertas de los sagrarios.

En la misma iglesia de la Anunciación se encuentra otro Niño Jesús pintado en la puerta del tabernáculo, obra de Juan de Roelas, del conjunto-retablo del Dulce Nombre de Jesús. En 1606, "se hizo también el retablo del altar mayor. [...]

${ }^{51}$ DE SOLÍS Y FEDERIGUI, Antonio: Los dos espejos..., op. cit., pp. 86 y 105-107.

${ }^{52}$ CORNEJO VEGA, Francisco Javier: "Noticias de Francisco de Herrera el Viejo en Madrid del retablo mayor del colegio de San Basilio de Sevilla”, Archivo Español de Arte, 316, 2006, pp. 363-370. 
Toda la obra es tan grave, seria y majestuosa como ella misma lo dice" 53 . Compositivamente, el Niño es bastante distinto del que nos ocupa: representado como Cristo resucitado, pues lleva el manto púrpura y la cruz con banderola, está sentado apoyando el pie derecho sobre la calavera de Adán mientras una serpiente pasa por encima de él. La acumulación de todos estos símbolos que representan el triunfo sobre la muerte y el pecado está dulcificada por el cuerpecillo regordete, la cara sonriente y la rubicundez del Niño, que contrapone su corta edad al papel trascendente que representa.

Otro Niño Jesús pintado por Francisco Pacheco hacia 1615 en la puerta del sagrario de la capilla de la Virgen de la Milagrosa del desaparecido hospital de la Mendicidad de San Fernando se encuentra hoy en una colección particular de Sevilla ${ }^{54}$.

En 1621 y 1622 sendos documentos aclaran que había un Niño Jesús pintado por Juan de Uceda en la puerta del sagrario, flanqueado por otras cuatro pinturas, del retablo de San Juan Bautista del convento de Nuestra Señora del Socorro de Sevilla ${ }^{55}$. Según creen Valdivieso y Serrera, un Niño Jesús pintado sobre tabla, de 56 por $40 \mathrm{~cm}$, de propiedad particular, y obra característica de Uceda, puede ser el procedente de este tabernáculo ${ }^{56}$. Sin embargo, el retablo de San Juan Bautista, en la actualidad en la iglesia de la Anunciación, tiene en el centro del banco un precioso San Juanito pintado sobre lo que fue la puerta de un sagrario, pues conserva la cerradura, que, por el tamaño, 39 por $25 \mathrm{~cm}$, encaja perfectamente en el espacio que le corresponde en el retablo mientras que el anteriormente citado sería demasiado grande. Este San Juanito es, con toda probabilidad, al que se refieren los textos pues su representación aquí es adecuada para un retablo del Bautista. La confusión de los documentos quizás pueda deberse a que la representación de San Juanito es parecida a la del Niño Jesús como Buen Pastor. Así lo vemos en el retablo de San Francisco de la iglesia de Santiago de Madrid, obra de Alonso $\mathrm{Cano}^{57}$, sobre la puerta del sagrario del retablo mayor de la iglesia de Nuestra Señora de la Cabeza de Ogíjares (Granada) o en el altar mayor de

${ }^{53}$ DE SOLÍS Y FEDERIGUI, Antonio: Los dos espejos..., op. cit., p. 227.

${ }^{54}$ VALDIVIESO GONZÁLEZ, Enrique y SERRERA CONTRERAS, Juan Miguel: Historia de la pintura española: escuela sevillana del primer tercio del siglo XVII. Madrid, 1985, p. 72.

${ }_{55}$ BAGO Y QUINTANILLA, Miguel y SANCHO CORBACHO, Heliodoro: $D o c u$ mentos para la Historia del Arte en Andalucía. T. II. Sevilla 1930, pp. 233-234; y MURO OREJÓN, Antonio: Documentos para la Historia del Arte en Andalucía. T. VIII. Sevilla, 1935 , p. 74.

56 VALDIVIESO GONZÁLEZ, Enrique y SERRERA CONTRERAS, Juan Miguel: Historia de la pintura..., op. cit., p. 218.

${ }^{57}$ DÍAZ MORENO, Félix: "Alonso Cano y el retablo de San Francisco de la iglesia de Santiago de Madrid”, Anales de Historia del Arte, volumen extraordinario, 2008, p. 287. 
la iglesia de San Bartolomé de Higuera la Real, que anteriormente fue la del colegio de la Compañía de Jesús ${ }^{58}$.

Como otros tantos pintores de renombre del siglo XVII Francisco de Zurbarán también pintó hacia 1635 un Niño Jesús en la puerta del sagrario del altar colateral del lado de la epístola que estaba en la iglesia de los Trinitarios de Sevilla ${ }^{59}$, hoy en el museo del Hermitage de San Petersburgo ${ }^{60}$.

Las pinturas del Niño Jesús como Salvador o como Buen Pastor proliferaron en las puertas de los sagrarios pero también han sido abundantes las desapariciones, unas por fuego, otras por enajenación. En 1621-1622 Juan del Castillo realizó el retablo mayor de la parroquia de Brenes, que tenía un Niño pintado en el sagrario, desaparecido en 1936, lo mismo que el que había en la puerta del sagrario del retablo mayor de la iglesia de Los Palacios (Sevilla) ${ }^{61}$, realizado por Pablo Legot entre 1629 y $1634^{62}$.

Fecha de recepción: 18 de octubre de 2017

Fecha de aceptación: 12 de abril de 2018

58 BNE (Biblioteca Nacional de España), Mss/20519, FERNÁNDEZ DÁVILA, Francisco: Historia del colegio de la Compañía de Jesús de la villa de Higuera la Real: Ocasión, origen y progreso de esta fundación votada al Santísimo Cristo de la humildad y paciencia por el ilustre Francisco Fernández Dávila, caballero de la Orden de Santiago.

${ }_{59}$ CEÁN BERMÚDEZ, Juan Agustín: Diccionario de los más ilustres profesores de las Bellas Artes en España. T. III. Madrid, 1800, pp. 50-51.

60 VALDIVIESO GONZÁLEZ, Enrique: "La santa infancia en la pintura barroca sevillana", Boletín de la Real Academia de Buenas Letras, Minervae Baeticae, 36, 2008, p. 11.

${ }^{61}$ VALDIVIESO GONZÁLEZ, Enrique y SERRERA CONTRERAS, Juan Miguel: Historia de la pintura..., op. cit., p. 318 y 287-289.

${ }^{62}$ LÓPEZ MARTÍNEZ, Celestino: Arquitectos, escultores y pintores vecinos de Sevilla. Sevilla, 1928, p. 80; y LÓPEZ MARTÍNEZ, Celestino: Retablos y esculturas de traza sevillana. Sevilla, 1928, p. 151. 


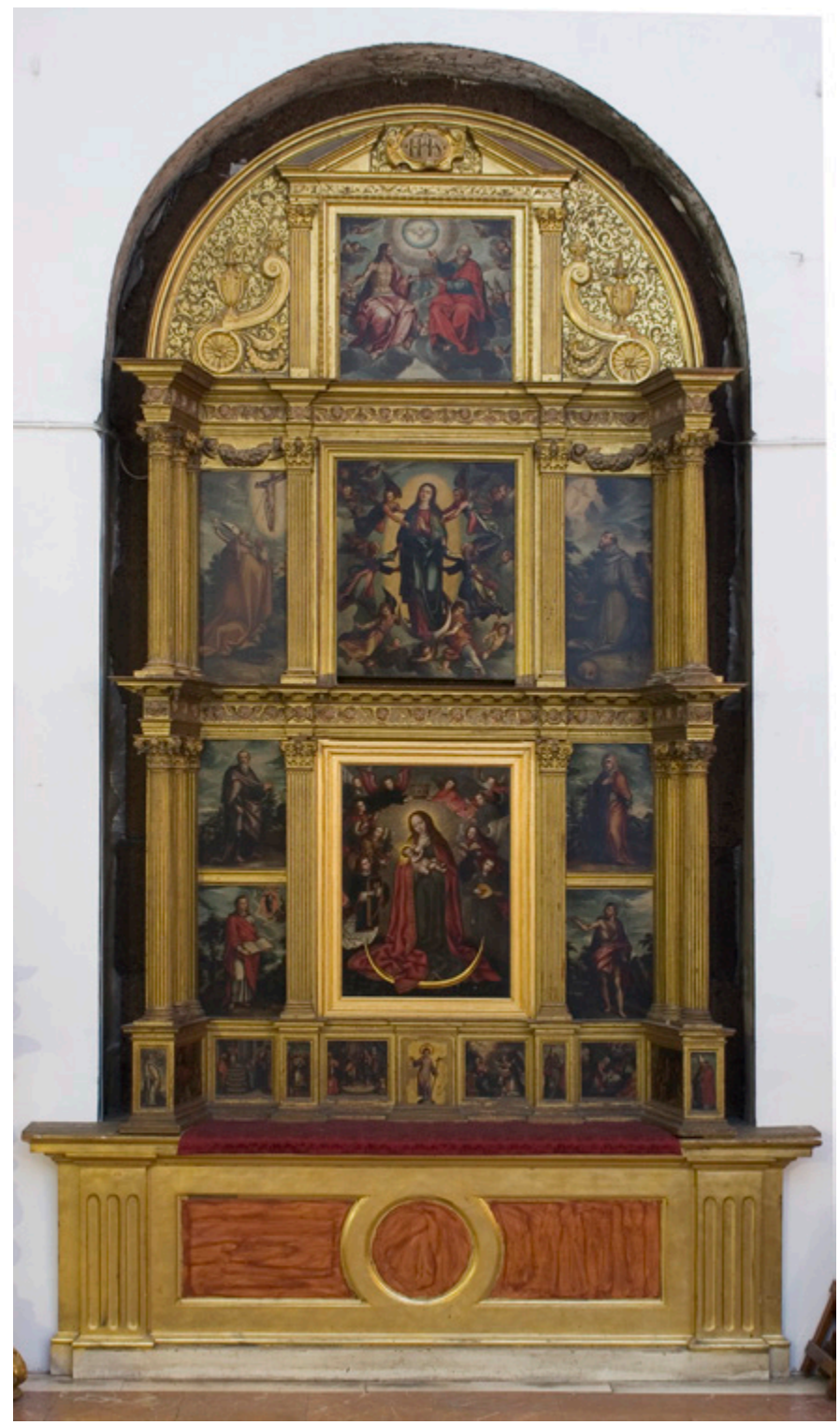

Figura 1. Retablo de la Virgen de Belén, siglo XVI, iglesia de la Anunciación, Sevilla. 


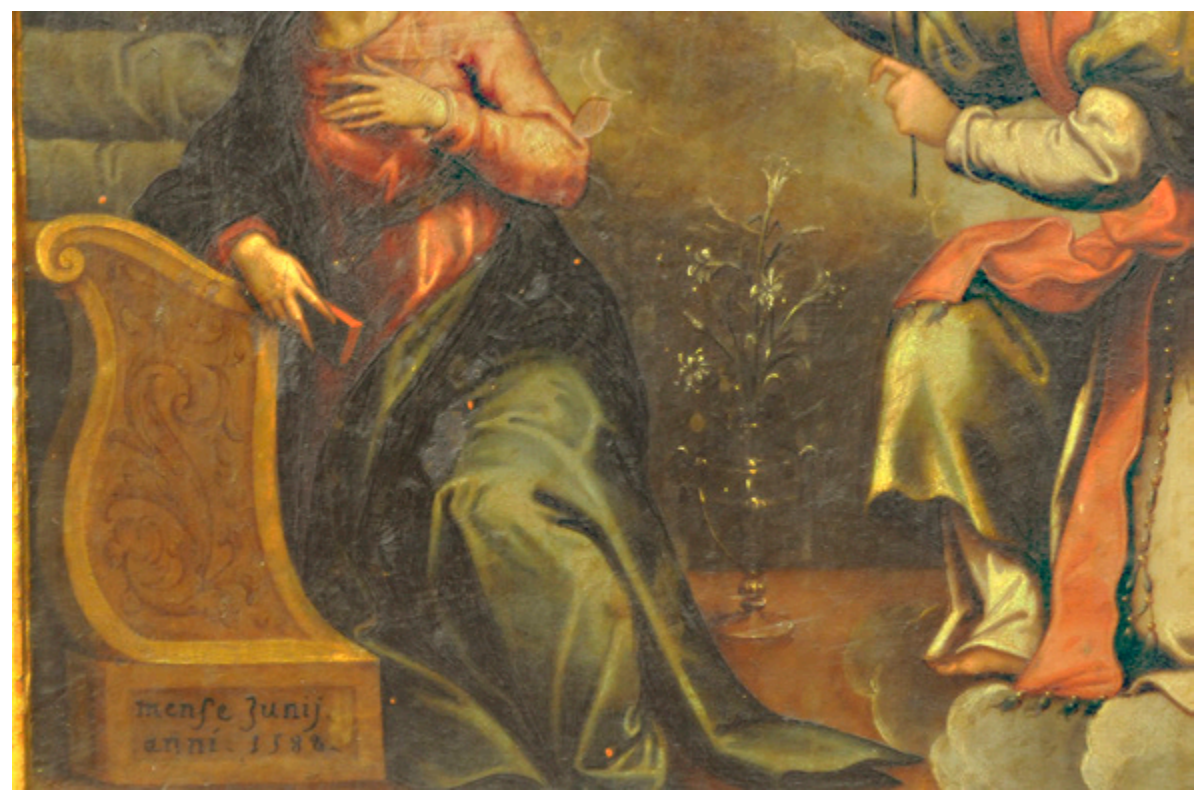

Figura 2. Retablo de la Virgen de Belén (detalle), 1588, iglesia de la Anunciación, Sevilla. 


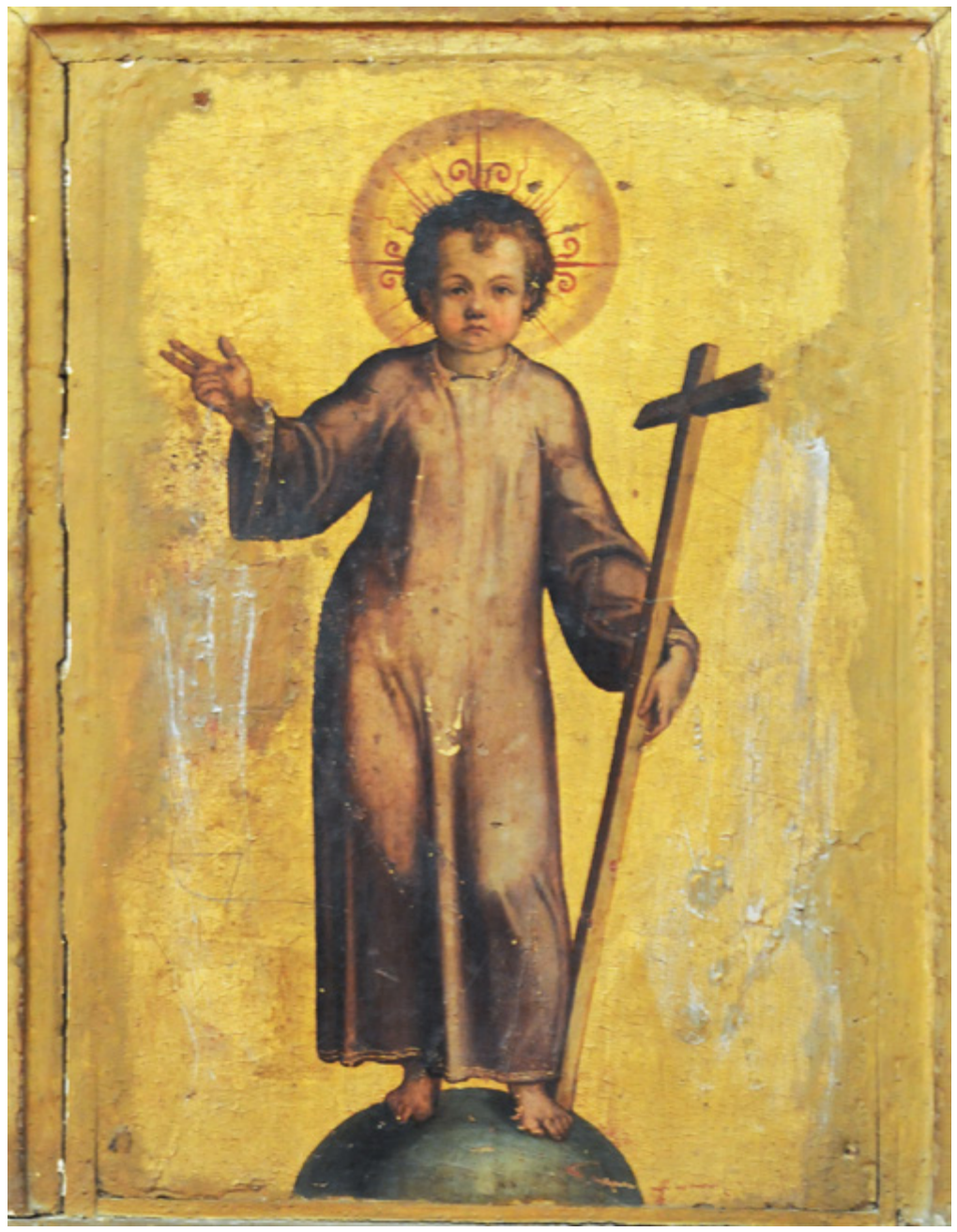

Figura 3. Andrés Ramírez, Niño Jesús, segundo tercio del siglo XVI, retablo de la Virgen de Belén, iglesia de la Anunciación, Sevilla. 


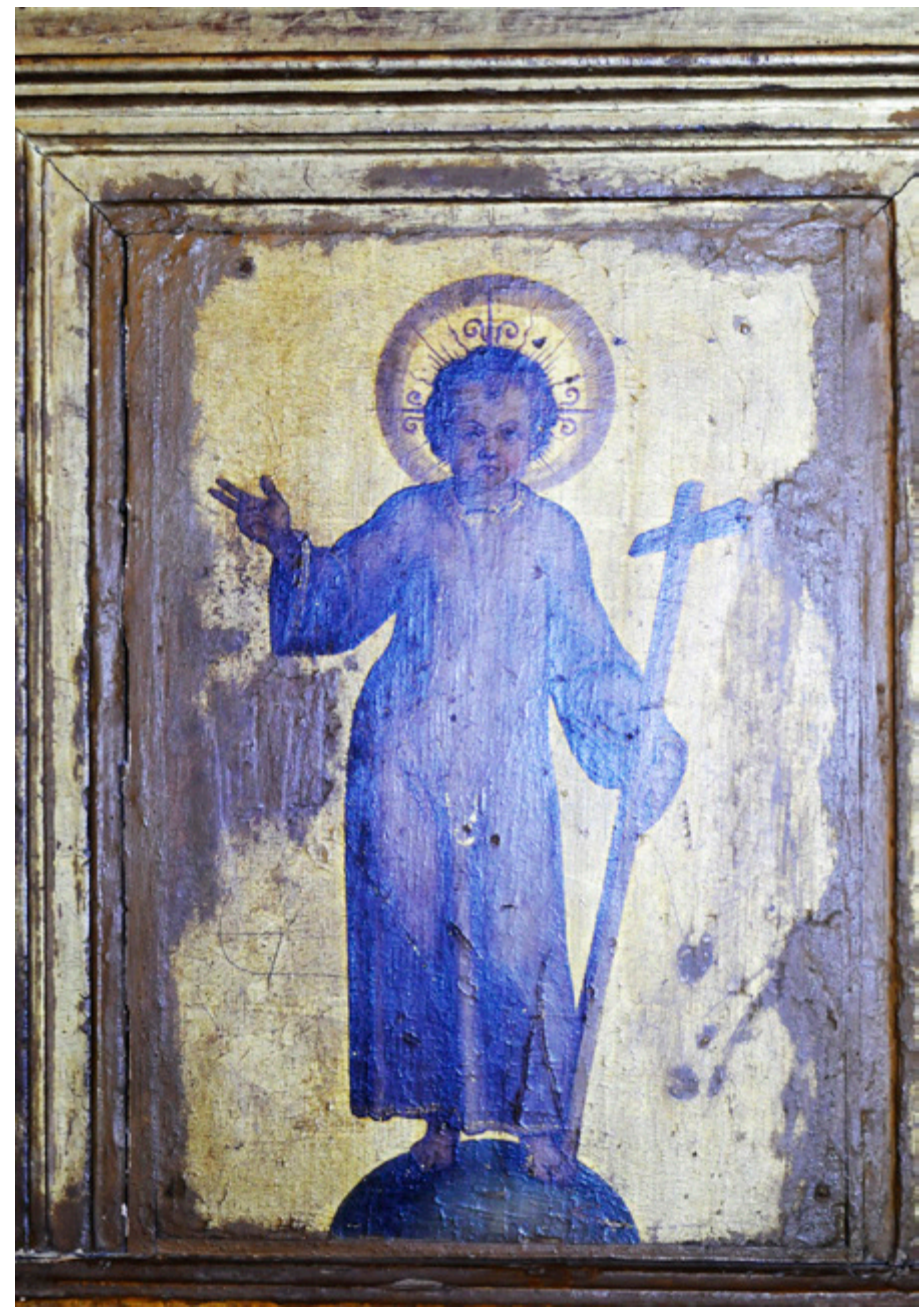

Figura 4. Andrés Ramírez, Niño Jesús, segundo tercio del siglo XVI, retablo de la Virgen de Belén, iglesia de la Anunciación, Sevilla. 


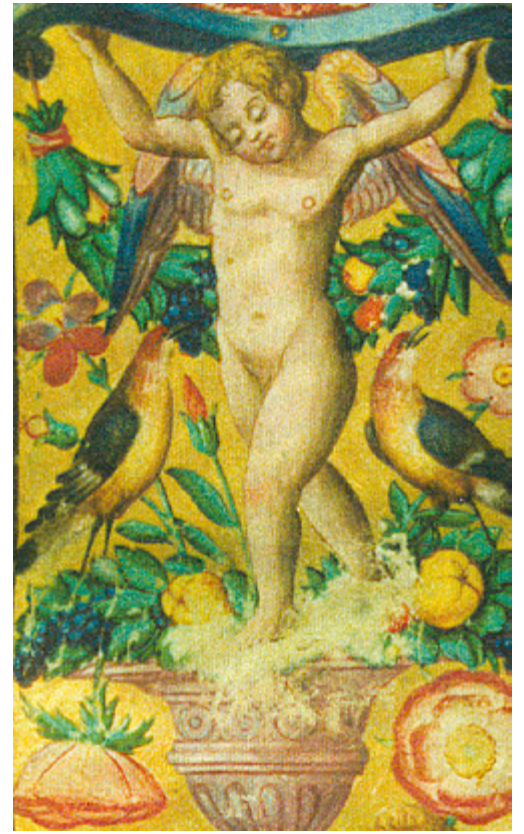

Figura 5. Andrés Ramírez, Ángel tenante, 1588, Libro de coro 62, folio 2 vuelto, orla exterior, catedral de Sevilla.

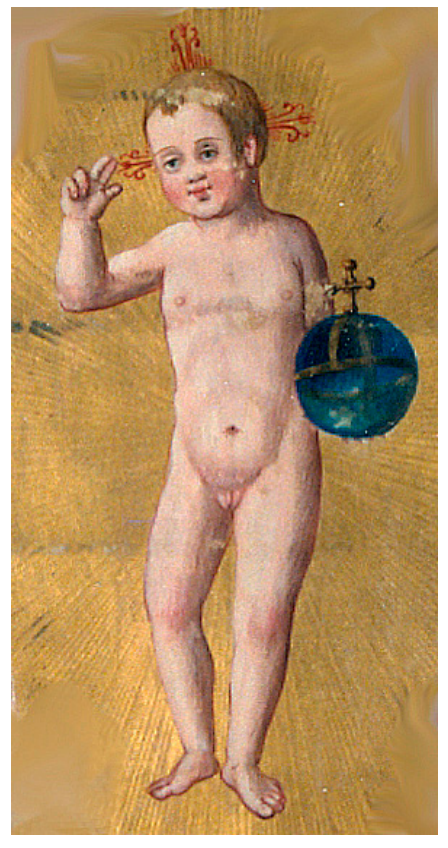

Figura 6. Andrés Ramírez, Niño Jesús, segundo tercio del siglo XVI, Libro de coro 60, folio 7 vuelto, catedral de Sevilla. 


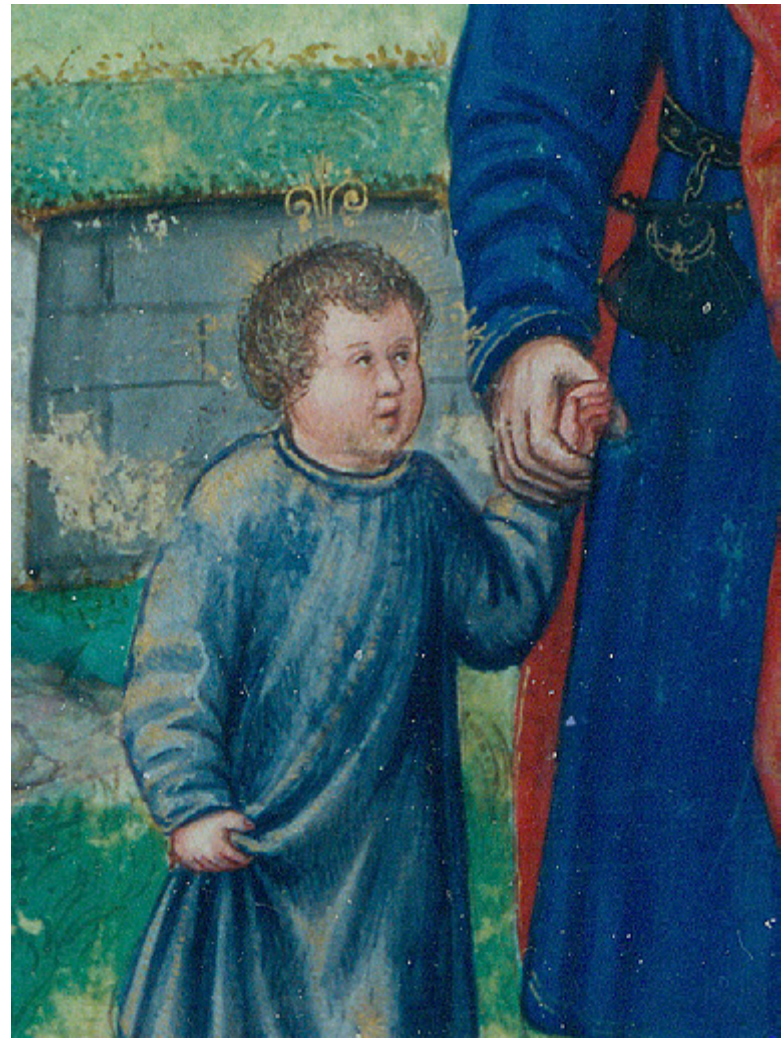

Figura 7. Andrés Ramírez, San José con el Niño de la mano, 1543, Libro de coro 40, folio 1 vuelto, catedral de Sevilla. 


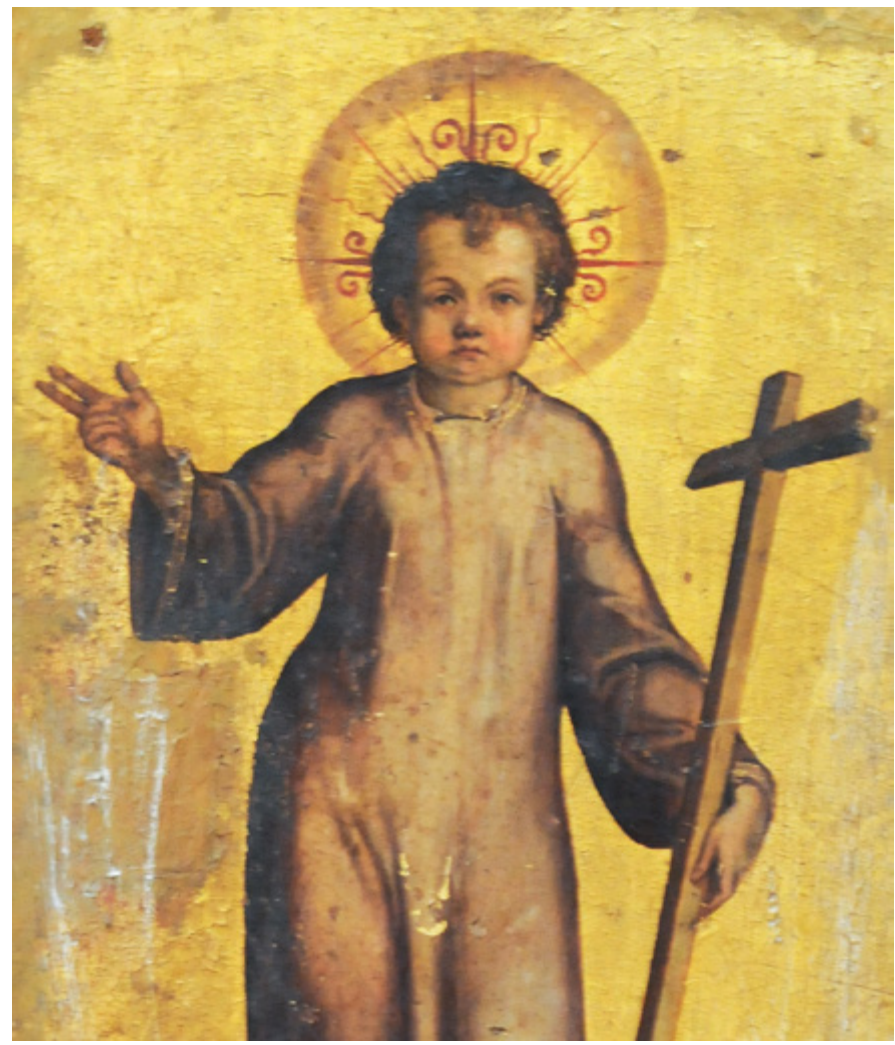

Figura 8. Andrés Ramírez, Niño Jesús (detalle), segundo tercio del siglo XVI, retablo de la Virgen de Belén, iglesia de la Anunciación, Sevilla. 